\title{
STUDY ON RIGID HOMOGENIZATION METHOD AND MODEL OF MASONRY UNDER DIFFERENT BRICKLAYING METHODS BASED ON REGULAR TESSELLATION THEORY
}

\author{
CHUNXIA YANG ${ }^{*}$, SHU CHEN, CHENYI LI, AND NAN ZENG \\ School of architecture and civil engineering \\ Changsha University of Science and Technology (CSUST) \\ Changsha, 410114 Hunan, China \\ e-mail: ycx3346@126.com (*corresponding author) \\ \{874939885,972898716,1254453392\}@qq.com
}

Keywords: Masonry Structure, Homogenization Theory, Tessellation Theory, RVE, Anisotropy, Bricklaying Method, Finite Element Method

\begin{abstract}
The brick and tile of the existing masonry structures are precious, so it is not feasible that the components are used as the dismantling unit for maintenance and reinforcement. The homogenization method is an effective multi-scale calculation method, which can be used to establish the analysis model of masonry on the mesoscopic-level. The plane tessellation deconstruction method of masonry structure is proposed, exploring the internal tessellation laws of masonry under different bricklaying methods, and the theoretical system of periodic plane segmentation of masonry is established. Based on regular tessellation theory, the plane segmentation of masonry structures under three kinds of bricklaying methods is periodically carried out through rectangular unit lattice. Deconstructing the smallest element of the tessellation form, the boundary condition of equivalent volume element (RVE) is derived. On the premise of selecting reasonable material parameters, RVE models under three kinds of bricklaying methods are built by finite element software ABAQUS, and the equivalent parameters are obtained to realize the simulation analysis of masonry structure based on micro-mechanics. The results show that the strength of running bonding RVE is higher than that of the other two kinds, and the strength of header bonding RVE is the lowest. The finite element results are compared with the compressive strength results of the specimens under three kinds of bricklaying methods in the existing tests. The results are in good agreement, which shows that the compressive capacity of masonry structures with homogenization simulation under three kinds of bricklaying methods is reliable while homogenization reflects the mechanical characteristics of masonry structure as a whole. The rigid homogenization method based on regular tessellation theory takes brick by brick as components to be dismantled and replaced in the ancient architecture, which opens a new way for the fine analysis of masonry structure. The rigid homogenization method maximizes the protection of the ancient masonry structure, which is of great significance for the protection of human cultural heritage.
\end{abstract}




\section{INTRODUCTION}

Masonry structure, as a composite structure composed of two different materials of brick and mortar, has different deformation and mechanical properties under different brick arrangement modes. As the weak link in masonry structure, mortar, its existence makes the destruction form and mechanical properties of masonry structure more complicated than other building forms. Homogenization method is an effective method to analyze the macro and micro-mechanical properties of composite materials at present. The characteristics of the each material of masonry structure are fused together, equivalent parameters are given to the equivalent volume unit, and then the equivalent volume unit is applied to the whole. Homogenization method can not only study the equivalent properties and deformation of composite materials from the mesoscopic level, but also check the overall response of the structure from the macroscopic level. It has been widely applied in engineering.

The concept of RVE was first proposed in the study of mechanical properties of masonry by L.Gambarotta ${ }^{[1]}$. Considering the three aspects of bricklaying methods, thickness and homogenization steps, the rigid homogenization theory is put forward to avoid the deficiencies of the gradual homogenization thought by A.Anthoine ${ }^{[2]}$. The homogenization theory of periodic medium is adopted, and the brick and mortar models are assumed to be of continuous failure type by P.Pegon ${ }^{[3]}$. In addition, the two assumptions (plane stress assumption and plane strain assumption) are compared, and the differences between the two are obtained. The homogenization method called "Second-order" is proposed by A.Anthoine ${ }^{[4]}$

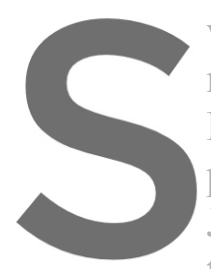
Which can further extend the rigid homogenization theory
masonry structures. Masonry homogenization method was
Daquan Wang[5]. Based on the research of composite me
properties of RVE element are analyzed and periodic bounda
Jimei Shen ${ }^{[6]}$. The influence of different bricklaying methods the compressive properties of masonry is analyzed by minimum basic unit is analyzed, and the selected two-dimensional basic unit is divided in Chenyi Li ${ }^{[9]}$.

Homogenization method can be used as an effective method to study the mechanicai properties of unreinforced masonry structures. In the equivalent volume unit with continuous periodicity, the different material properties and bricklaying methods of constituent materials will have different effects on mechanical properties. Therefore, reliable material parameters are selected and the form of separate modeling is adopted. The mechanical properties and deformation properties of RVE selected under common different masonry forms are simulated by ABAQUS analysis software. The stress-strain relationship of each equivalent volume element is analyzed, and the RVE equivalent parameters in all directions are calculated. The RVE isotropic equivalent parameters are applied to the finite element model based on the existing tests. The simulated values are compared with the test values and the error sources are analyzed. 


\section{THE THEORY OF PERIODIC MASONRY PLANE SEGMENTATION}

\subsection{Application of Fit Theory}

The ancient masonry structure that condensed the wisdom and sweat of the ancient laboring people witnessed the 5000-year civilization and history of China. However, due to man-made destruction and natural erosion, it is imperative for researchers to maintain ancient masonry buildings. Therefore, the conjunction theory is introduced to study the homogenization of masonry structure, in order to provide an effective method for the maintenance of ancient masonry buildings.

Masonry structure, a human creation that has been passed on for thousands of years, has not been taken as a plane division art by predecessors to explore internal tessellation laws. Tessellation composition refers to the regular arrangement of closed graphic objects that have no overlap and no gaps. Tessellation deconstruction refers to the regular plane division of the overall coincidence shape. The former emphasizes that graphic units are used to fill the whole skeleton, while the latter emphasizes that the whole plane is divided by unit graphics. Both are mathematical problems of periodically dividing two-dimensional planes essentially, involving the principle of mathematical symmetry. In the process of tessellation, each graphic element must follow the conditions of edge symbiosis and repeated continuity.

The first step of the masonry homogenization method is to divide the masonry structure periodically. The systematic plane division of the masonry requires a thorough understanding of internal tessellation masonry structure is the 2.2 Tessellation Laws and $\mathbb{P}$. Methods
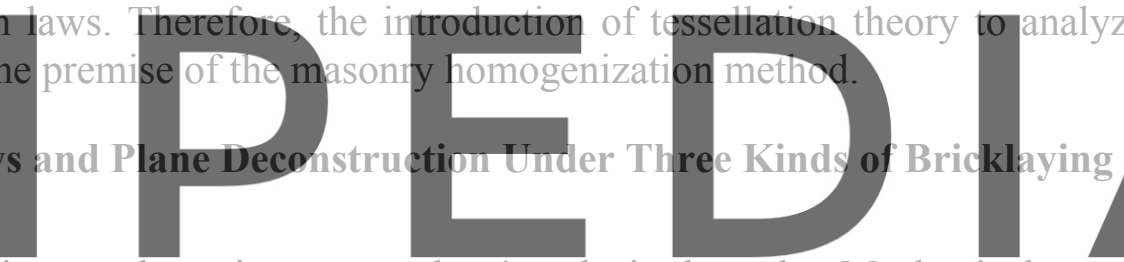

Many practical projects and previous researchers' analysis show that Mechanical properties

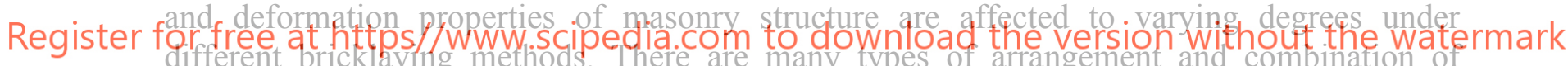
blocks in buildings. The RVE units of masonry under three common kinds of bricklaying methods are selected, as shown in figure 1:

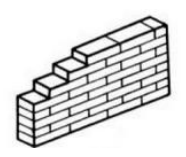

(a)

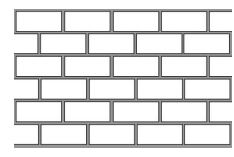

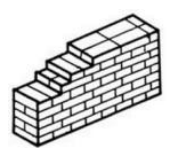

(b)

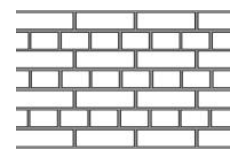

b)
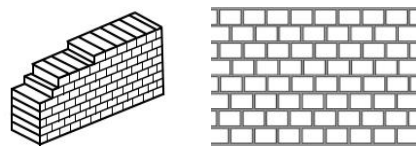

(c)

Figure 1: Three kinds of bricklaying methods selected (respectively running bonding; quarter bonding; header bonding)

The tessellation theory is introduced to analyse masonry structure. The basic unit components move in two different directions. Through translation, rotation, reflection and sliding reflection, a universal tessellation shape, i.e. a complete piece of wall, is generated in the plane. Taking running bonding as a representative to comprehensively consider, it is assumed that the size of the unit basic component of the tessellation shape (as shown in figure 2) is: 
$(x h) \times(y b)$

Where $h$ stands for the sum of block height and the thickness of horizontal mortar joint in running bonding masonry; $l$ stands for the sum of block length and the thickness of vertical mortar joint in running bonding masonry; $d$ stands for the overlapping amount of masonry walls, and the overlapping amount of running bonding masonry walls is $l / 2 ; x$ and $y$ stand for any positive integer.

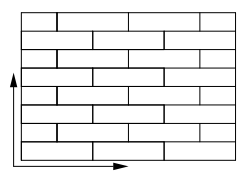

Figure 2: Coordinate system of the tessellation shape

Only when the basic unit components are uniformly and regularly formed into a rectangular, parallelogram, rhombus or regular hexagon array, can the wall be divided into a distributed tessellation shape by plane segmentation laws. For example, when $x=1, y=1$, there is rectangular basic components for the tessellation shape of running bonding masonry (as shown in figure 3, the half brick and half-thick mortar units surrounding three sides of the brick form a kind of rectangular basic components for the tessellation shape of running bonding masonry). Therefore, all kinds of basic shapes set are periodically divided into the

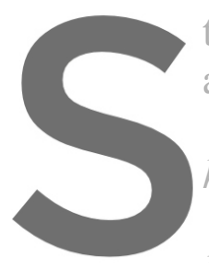
tessellation shape of rum are proposed, as shown

(1)The rectangular c

$h \times(l / 2)$;

(2)The parallelogram components $(x h) \times(y, h)$
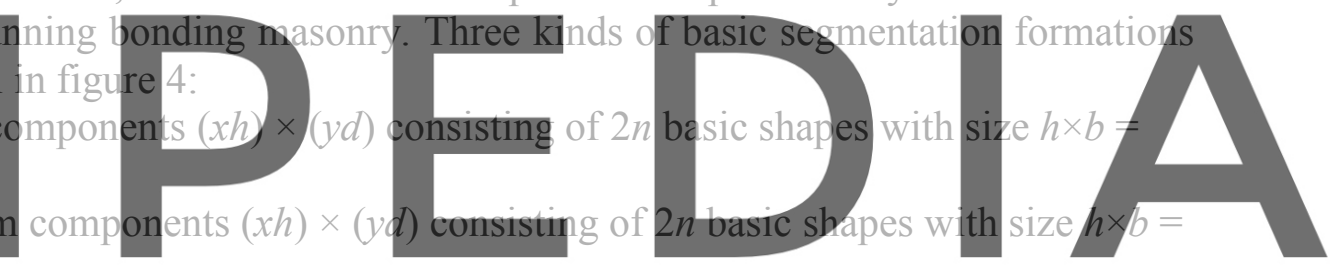
$h \times(l / 2)$;

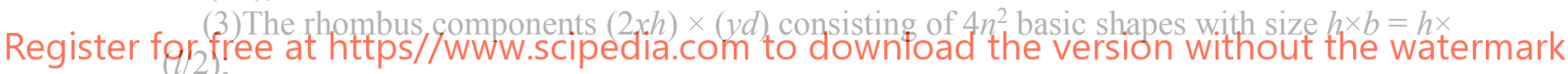
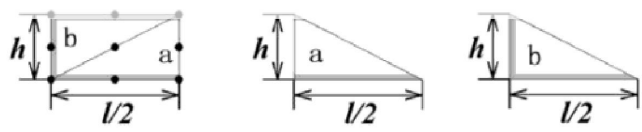

Figure 3: The rectangular components and its basic form of running bonding masonry

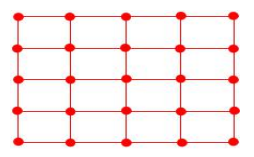

(a)

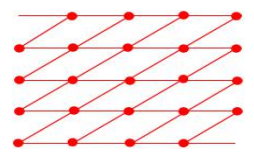

(b)

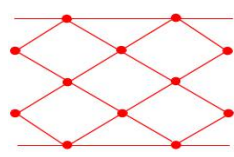

(c)

Figure 4: Three kinds of basic segmentation formation (respectively rectangle; diamond; parallelogram)

When $x$ and $y$ are any positive integers, the basic unit components may not be obtained by the three basic segmentation formations shown in figure 5 after division and division. Therefore, only the whole wall is divided into rectangles, and rectangular basic segmentation 
formations are adopted (figure 4(a)). The rectangular segmentation formations of part of the wall under three kinds of bricklaying methods is shown in figure 5:

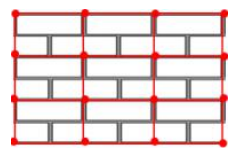

(a)

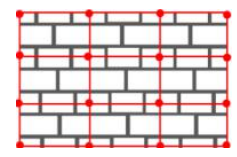

(b)

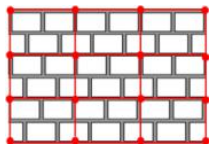

(c)

Figure 5: Partition of wall sheet matrix lattice in typical bricklaying methods (respectively running bonding; quarter bonding; header bonding)

Referring to the above-mentioned rectangular lattice division, the dimensions of the RVE unit of masonry selected under different assembling methods are shown in figure 6 :
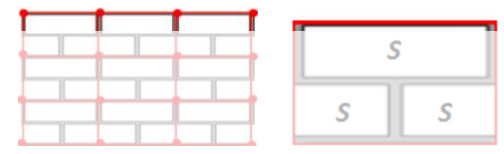

(a)
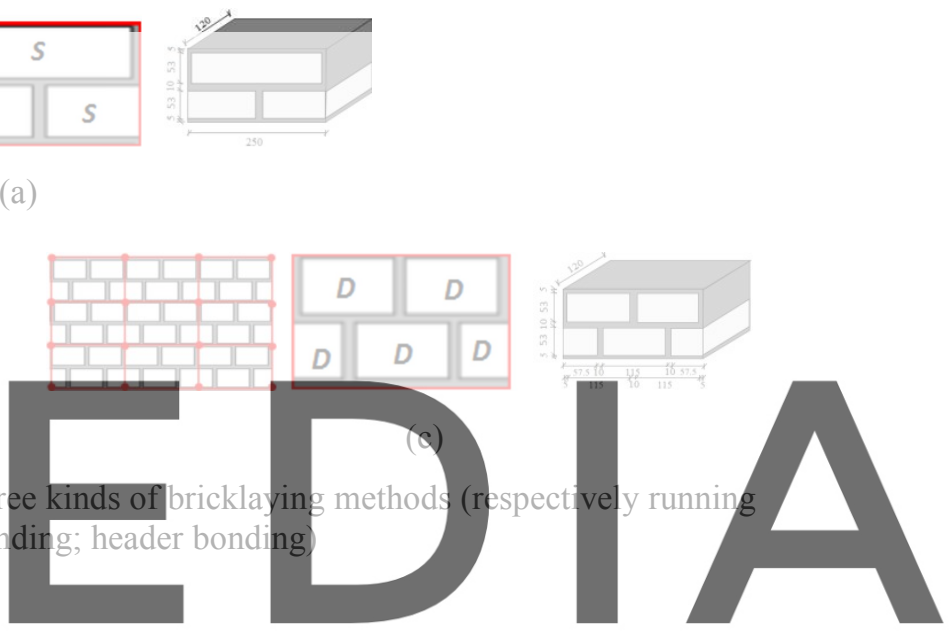

2.3 2-D Periodic Deseription

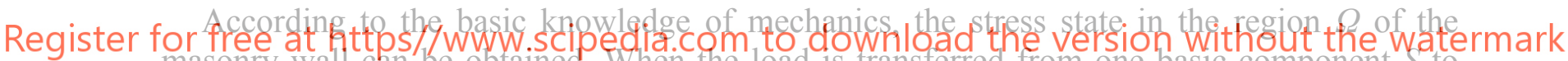
another basic component $S^{\prime}$, the following conditions can be established:

(1) The stress vector is continuous;

(2) The strain in the deformation process is coordinated with each other, and no separation or overlap occurs between basic components.

1) Periodic stress

Condition (1) means that stress is transferred from one side of the same component $S$ to its opposite side to meet the following requirements:

$$
\sigma\left(x+V_{\mathrm{a}}\right)+n \cdot\left(x+V_{\mathrm{a}}\right)=-\sigma(x) \cdot(x)(\text { On opposite sides of } \partial S)
$$

Because the outer normal $\mathrm{n}$ is anti-periodic symmetric, equation (2) can be simplified as:

$$
\left[\sigma\left(x+V_{\mathrm{a}}\right)-\sigma(x)\right] \cdot n(x)=0
$$

Therefore, the stress field $\sigma$ is called a periodic stress field. The stress vector $\sigma \cdot n$ is antiperiodic symmetric on $\partial S$.

\section{2) Strain-periodic displacement}

According to condition (2), opposite sides should completely coincide in shape after 
deformation. In other words, the relative displacement field of two opposite sides must be equal to the rigid displacement (translation or/and rotation). The basic component $S$ is transformed into the 2-D component shown in figure 7 :

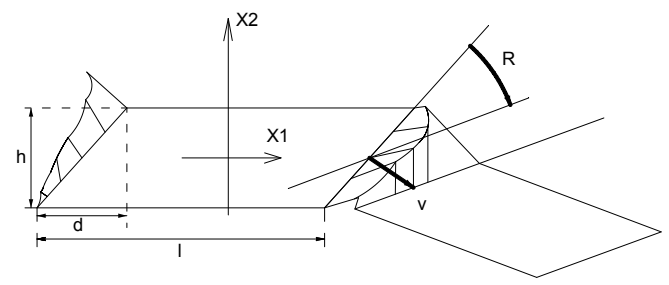

Figure 7: The basic components are compatible with the strain of opposite sides.

In the case of stack bonding pattern, this is expressed by:

$$
\begin{array}{lr}
u\left(x_{1}, h\right)-u\left(x_{1},-h\right)=V-Q x_{1} \mathrm{e}_{2} & x_{1} \in[-l, l] \\
u\left(l, x_{2}\right)-u\left(-l, x_{2}\right)=U-R x_{2} \mathrm{e}_{1} & x_{2} \in[-h, h]
\end{array}
$$

Where $u$ and $v$ are translation vectors; $R$ and $S$ are rotation constants.

Similarly, the further conclusion has been proved for running bonding masonry:

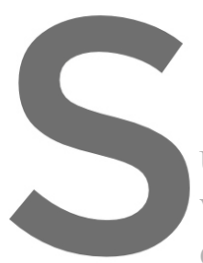

$$
\left.u\left(l / 2+x_{1}, h\right)-u\left(-l+x_{1},-h\right)=V-Q x_{1} \cdot e_{2}\right)
$$
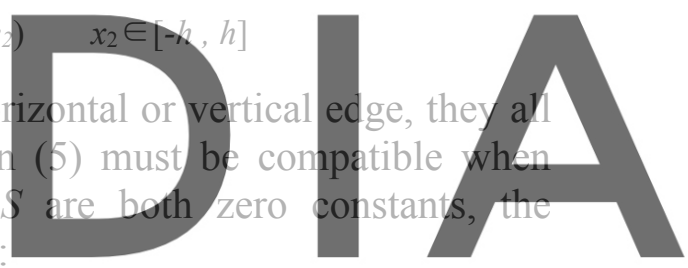

Where $d$ is the overlap amount.

Since it leads to a periodic strain field, such a displacement field $u$ is called strain-periodic. The strain-periodic displacement field can be expressed in the following form:

$$
\begin{gathered}
u(x)=E \cdot x+u^{p}(x) \\
u_{1}\left(x_{1}, x_{2}\right)=E_{11} x_{1}+E_{12} x_{2}+u_{1}^{p}\left(x_{1}, x_{2}\right) \\
u_{2}\left(x_{1}, x_{2}\right)=E_{21} x_{1}+E_{22} x_{2}+u_{1}^{p}\left(x_{1}, x_{2}\right)
\end{gathered}
$$

Where $E_{\alpha \beta}(\alpha, \beta=1$ or 2$)$ are four constants; $\mathrm{u}^{\mathrm{p}}(\mathrm{x})$ is periodic displacement field with equal values on any set of opposite sides of $\partial S$ :

$$
u^{p}\left(x+V_{\alpha}\right)=u^{p}\left(V_{\alpha}\right) \text { (On opposite sides of } \partial S \text { ) }
$$

The expression of the strain-periodic displacement field is derived from equations (7) and (8):

$$
u\left(x+V_{\alpha}\right)-u(x)=\mathrm{E} \cdot V_{\alpha}+\Omega \times V_{\alpha}
$$


As compared with equation (7), equation (9) only involves periodic relative displacement between two points on opposite sides.

\subsection{Realization and Application of Homogenization}

Because of periodic stress $\sigma$ (equation (3)) and the strain periodic displacement $u$ (equation (9)) of basic components deduced earlier, it is not necessary to calculate the whole specimen, but to focus on any component in the specimen. In order to obtain $\sigma$ and $u$ everywhere on the basic component, equilibrium conditions and constitutive relations must be added so that the problem to solve by equation (10) is:

$$
\begin{aligned}
\operatorname{div} \sigma & =0 \text { (on } S \text { ) } \\
\sigma & =f(\varepsilon(u))
\end{aligned}
$$

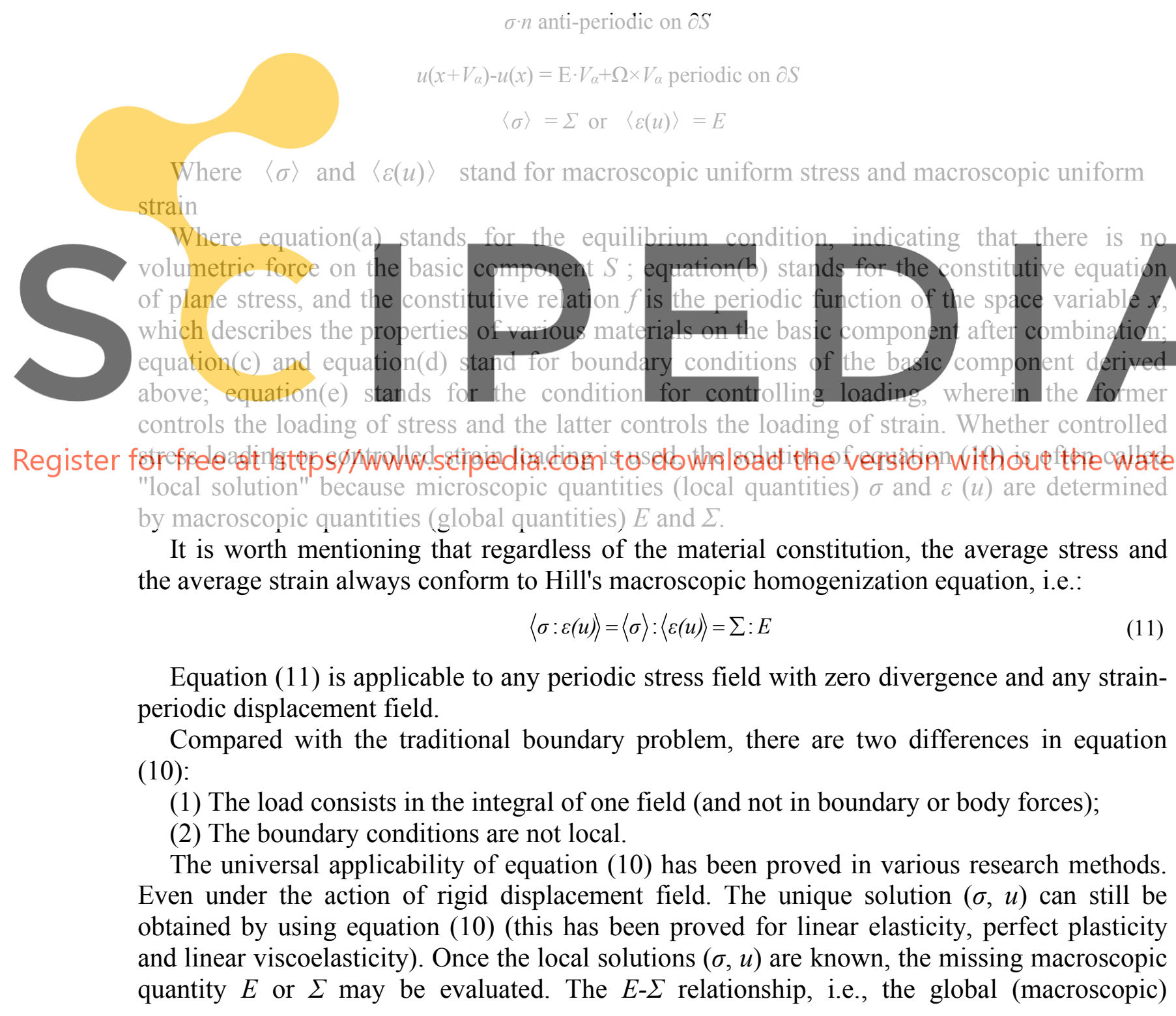


constitutive law of the composite material can be built by repeating this process to obtain enough groups of $E$ and $\Sigma$.

According to the definition above, if masonry is replaced by the fictitious homogeneous material obeying to this macroscopic constitutive law (homogenized material), the mechanical properties of the specimen subjected to a macroscopical homogeneous loading remain consistent with those of the masonry specimen. This makes it unnecessary to show independent basic components when the finite element software is used to calculate the overall mechanical properties of masonry structures subjected to in-plane loads. Instead, as long as the homogeneous materials are used to build the same structure under the same loading conditions, the an-isotropic homogeneous structure is flexibly meshed (which cannot be realized on the original an-isotropic non-homogeneous masonry structure). The conclusions similar to the original masonry structure are obtained after the appropriate finite elements are selected for calculation.

\section{MODEL BUILDING}

\section{The reduced integration unit C3D8R is selected. The finite element models of RVE under} three kinds of bricklaying methods are shown in figure 8.
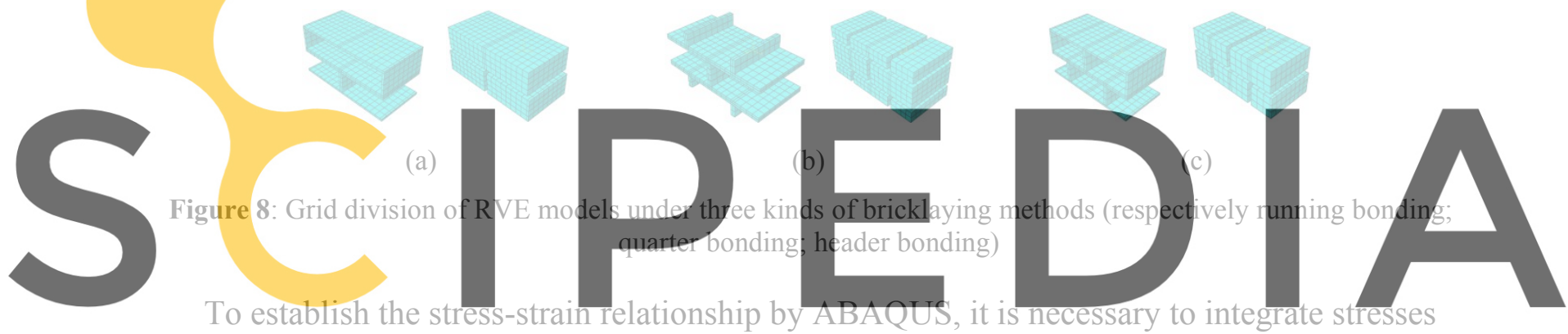

To establish the stress-strain relationship by ABAQUS, it is necessary to integrate stics

Register for free at https//www.scipedia.com to download the version without the watermark

$$
\begin{aligned}
& \bar{\sigma}_{\mathrm{ij}}=\frac{1}{V} \int_{V} \sigma_{\mathrm{ij}} \mathrm{d} V \\
& \bar{\varepsilon}_{\mathrm{ij}}=\frac{1}{V} \int_{V} \varepsilon_{\mathrm{ij}} \mathrm{d} V
\end{aligned}
$$

It is approximately believed that the average stress and strain of brick and mortar units are their average values respectively.

\section{EXTRACTION OF EACH EQUIVALENT PARAMETER}

\subsection{Uniaxial Stress-Strain Curves of RVE Models}

Average stress-strain curves of masonry under three kinds of bricklaying methods for uniaxial compression along the $\mathrm{x}, \mathrm{y}$ and $\mathrm{z}$ axes obtained by finite element software ABAQUS are shown in figure 9(a). Average stress-strain curves of the running bonding RVE model for uniaxial tension are shown in figure 9(b). Average stress-strain curves of the quarter bonding RVE model for uniaxial shear are shown in figure 9(c). Peak strains and ultimate strengths are shown in tables 1-3. 

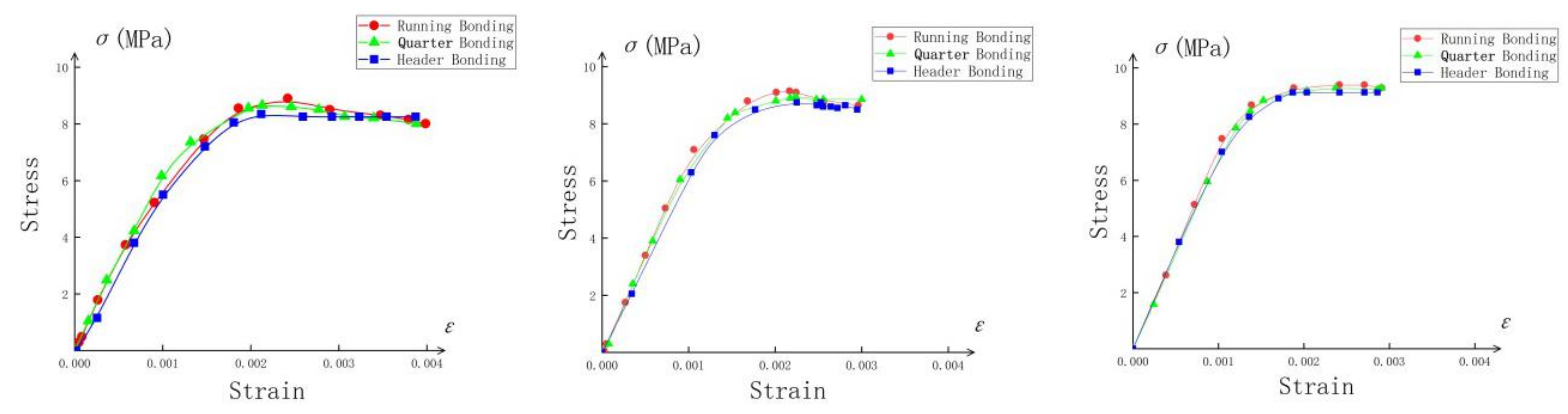

(a)

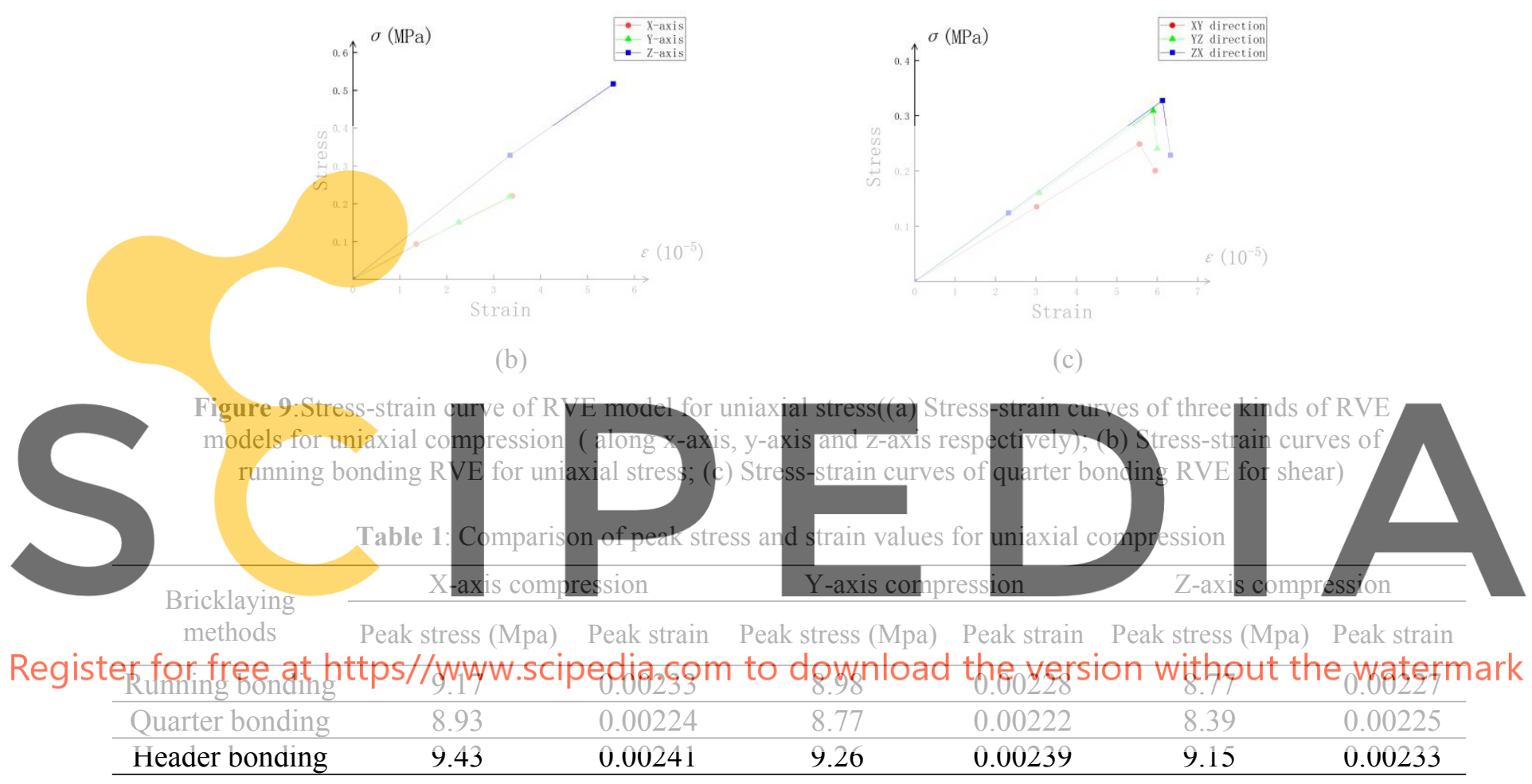

Table 2: Comparison of peak stress and strain values for uniaxial tension

\begin{tabular}{ccccccc}
\hline \multirow{2}{*}{$\begin{array}{c}\text { Bricklaying } \\
\text { methods }\end{array}$} & \multicolumn{2}{c}{ X-axis tension } & \multicolumn{2}{c}{ Y-axis tension } & \multicolumn{2}{c}{ Z-axis tension } \\
\cline { 2 - 7 } & Peak stress (Mpa) & Peak strain & Peak stress (Mpa) & Peak strain & Peak stress (Mpa) & Peak strain \\
\hline Running bonding & 0.219 & $3.23 \mathrm{E}-5$ & 0.225 & $3.38 \mathrm{E}-5$ & 0.517 & $5.53 \mathrm{E}-5$ \\
\hline Quarter bonding & 0.214 & $3.23 \mathrm{E}-5$ & 0.216 & $3.27 \mathrm{E}-5$ & 0.508 & $5.46 \mathrm{E}-5$ \\
\hline Header bonding & 0.201 & $3.08 \mathrm{E}-5$ & 0.203 & $3.11 \mathrm{E}-5$ & 0.498 & $5.41 \mathrm{E}-5$ \\
\hline
\end{tabular}

Table 3: Comparison of peak stress values for shear

\begin{tabular}{cccc}
\hline Bricklaying methods & XY-plane peak stress (Mpa) & YZ-plan peak stress (Mpa) & ZX-plan peak stress (Mpa) \\
\hline Running bonding & 0.29 & 0.33 & 0.37 \\
\hline Quarter bonding & 0.27 & 0.30 & 0.34 \\
\hline Header bonding & 0.22 & 0.29 & 0.31 \\
\hline
\end{tabular}




\subsection{Equivalent Parameters Along Different Axes}

When shear stress is not considered, the constitutive relation of elasticity of anisotropic materials is as follows:

$$
\left\{\begin{array}{c}
\varepsilon_{x} \\
\varepsilon_{y} \\
\varepsilon_{z}
\end{array}\right\}=\left[\begin{array}{ccc}
\frac{1}{E_{x}} & -\frac{v_{y x}}{E_{y}} & -\frac{v_{z x}}{E_{z}} \\
-\frac{v_{x y}}{E_{x}} & \frac{1}{E_{y}} & -\frac{v_{z y}}{E_{z}} \\
-\frac{v_{x z}}{E_{x}} & -\frac{v_{y z}}{E_{y}} & \frac{1}{E_{z}}
\end{array}\right]\left\{\begin{array}{c}
\sigma_{x} \\
\sigma_{y} \\
\sigma_{z}
\end{array}\right\}
$$

The initial part of the stress-strain curve obtained by finite element analysis is linear elasticity. When there is normal stress along only one axis, the equations for calculating the equivalent elastic modulus and Poisson's ratio along three axes are as follows:

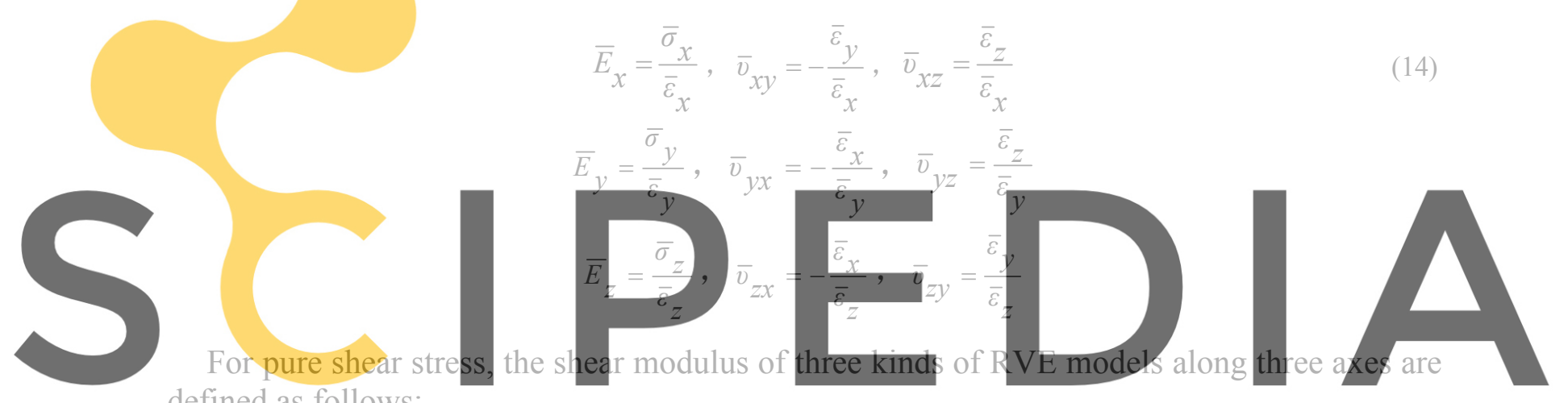

defined as follows:

Register for free at https//www.scipedia $\bar{c} c, 0 m$ to dōgwnload the version without the watermark

Table 4: Equivalent parameters of three kinds of RVE models along different axes

\begin{tabular}{|c|c|c|c|c|c|c|c|c|c|c|c|c|c|}
\hline \multirow{2}{*}{$\begin{array}{l}\text { Bricklaying } \\
\text { methods }\end{array}$} & \multicolumn{3}{|c|}{$\begin{array}{l}\text { The modulus of } \\
\text { elasticity }\end{array}$} & \multicolumn{6}{|c|}{ The Poisson's ratio } & \multicolumn{3}{|c|}{$\begin{array}{l}\text { An-isotropic shear } \\
\text { modulus }\end{array}$} & \multirow[t]{2}{*}{$\begin{array}{c}\text { Percentage } \\
\text { of mortar } \\
\text { content } \\
\end{array}$} \\
\hline & $\overline{\mathrm{E}}_{\mathrm{x}}$ & $\overline{\mathrm{E}}_{\mathrm{y}}$ & $\overline{\mathrm{E}}_{\mathrm{z}}$ & $\bar{v}_{x y}$ & $\overline{\mathrm{v}}_{\mathrm{yz}}$ & $\overline{\mathrm{v}}_{\mathrm{xz}}$ & $\overline{\mathrm{v}}_{\mathrm{yx}}$ & $\overline{\mathrm{U}}_{\mathrm{zy}}$ & $\overline{\mathrm{v}}_{\mathrm{zx}}$ & $\overline{\mathrm{G}}_{\mathrm{xy}}$ & $\overline{\mathrm{G}}_{\mathrm{yz}}$ & $\overline{\mathrm{G}}_{\mathrm{zx}}$ & \\
\hline Running bonding & 7134 & 6538 & 7579 & 0.184 & 0.174 & 0.180 & 0.179 & 0.198 & 0.196 & 2547 & 2603 & 3219 & 19.24 \\
\hline Quarter bonding & 6842 & 6317 & 7263 & 0.180 & 0.168 & 0.175 & 0.176 & 0.195 & 0.193 & 2538 & 2592 & 3112 & 20.92 \\
\hline Header bonding & 6486 & 6055 & 6723 & 0.172 & 0.165 & 0.167 & 0.169 & 0.187 & 0.186 & 2498 & 2563 & 3106 & 22.60 \\
\hline
\end{tabular}

The strengths of running bonding RVE selected are much higher than those of the other two kinds along different axes and the strengths of header bonding RVE selected are the lowest. Mechanical properties of RVE are affected by the placement of mortar joint and the overall volume occupied by mortar joint. In addition, there are some differences in the compressive strength of the three kinds of RVE models along different axes of $\mathrm{X}, \mathrm{Y}$ and $\mathrm{Z}$, 
which is not only related to bricklaying methods, but also related to the sizes along each axis. The compressive stiffness of masonry is inversely proportional to the mortar content. The smaller the mortar content is, the greater the compressive stiffness of masonry, which conforms to the theoretical facts and the variation law of equivalent elastic modulus.

\section{ANALYSIS AND SIMULATION OF RVE MODEL}

The data of compressive tests in the structural test center of Changsha University of Science and Technology by Zhiwei $\mathrm{Hu}^{[10]}$ is used as comparison. Only the running, quarter, and header RVE models are selected for analysis.

\subsection{Comparison of Compressive Strength}

Simulated and experimental values of the ultimate compressive strength of the three kinds of specimens are respectively shown in table 5:

Table 5: Simulation values (test values) of ultimate compressive strength

\begin{tabular}{ccccc}
\hline Bricklaying methods & Stress area $\left(\mathrm{mm}^{2}\right)$ & Failure load $(\mathrm{kN})$ & Compressive strength(MPa) & Error(\%) \\
\hline Quarter bonding & 56350 & $122(113)$ & $2.130(2.005)$ & 7.63 \\
\hline Header bonding & 117600 & $236(220)$ & $2.001(1.871)$ & 6.95 \\
\hline Running bonding & 117600 & $239(214)$ & $2.032(1.820)$ & 11.6 \\
\hline
\end{tabular}

\subsection{Comparison of Compressive Strength}

Test values and simulation values of elastic modulus are shown in table 6:

Table 6: Comparison of elastic modulus of specimens

\begin{tabular}{cccc}
\hline Bricklaying methods & Test value (MPa) & Simulation value(MPa) & Error(\%) \\
\hline Quarter bonding & 1335 & 1465 & 9.7 \\
\hline Header bonding & 1066 & 1152 & 8.1 \\
\hline Running bonding & 1027 & 1179 & 14.8 \\
\hline
\end{tabular}

\subsection{Results Analysis}

The maximum error of compressive strength is $11.6 \%$ (less than $15 \%$ ), which is within the acceptable range, indicating that the homogenization method is reliable for simulating compressive strength of masonry structure under three kinds of bricklaying methods.

From the data comparison, it can be concluded that the general trend of stress-strain simulation curves and test curves is consistent, while test values of the elastic modulus of the specimens under different bricklaying methods are quite different from simulation values. The reason is that strength values itself has certain deviation, and whether the strength is accurate or not directly affects values of the elastic modulus. Moreover, by using homogenization method, although the bond-slip effect at the interface cannot be simulated in the finite element model established by RVE, it can better simulate the mechanical characteristics of masonry structure as a whole. 


\section{CONCLUSION}

- On the premise of the tessellation theory, the whole wall under three common bricklaying methods is divided by using the rectangular division lattice. Three kinds of representative volume element (namely RVE) capable of generating universal tessellation shapes are obtained.

- $\quad$ The theory of periodic masonry plane segmentation is established, and the minimum component of the tessellation shapes is deconstructed, and the boundary conditions of equivalent volume element (RVE) are derived.

- $\quad$ On the premise of selecting reasonable material parameters, RVE models under three kinds of bricklaying methods are established, and the corresponding equivalent parameters are obtained. The results of finite element software are compared with the tests results. The results are in good agreement, which shows that the homogenization method is reliable for simulating compressive strength of masonry structure under three kinds of bricklaying methods and can reflect the stress characteristics of masonry structure as a whole.

Acknowledgements. The research is supported by the National Natural Science Foundation of China (Grant Nos. 51678067, 51808054). This support is gratefully acknowledged.

\section{REFERENCES}

[1] L.Gambarotta and S.Lagomarsino. Damage models for the seismic response of brick masonry shear walls. Part I: The mortar joint model and its applications. Earthquake Engineering and Structural Dynamics, (1997), 26(3): 423-439

[2] Anthoine, A. Derivation of the in-plane elastic characteristics of masonry through homogenization theory. International Journal of Solids and Structures, (1995)32, pp. 137 163.

[3] P.Pegon and A. Anthoine, Numerical strategies for solving continuum damage problems with softening Application to the homogenization of masonry, Computers and Structures, (1997)64, pp. 623-642, .

[4] A.Anthoine. Second-order homogenization of functionally graded materials. Inter-nation Journal of Solids and Structures.(2010)47, pp.1477-1489

[5] Daquan Wang. Nonlinear Analysis of Masonry Applying the RVE Homogenization Methods. (2002), pp.45-60

[6] Jimei Shen. Study on Homogenization Process of Masonry and Its Applications Using Numerical Simulation. (2012), pp.29-60

[7] Yalin Li. Study on compressive behavior of cross bore block masonry under different masonry methods. (2015), pp.20-42

[8] Yaying Wu. Research on the Rigid Homogenization Theory of Masonry Structures Based on Regular Tessellation Theory. (2012), pp.33-50

[9] Chengyi Li. Study on the Rigid Homogenization Model of Masonry under Different Masonry Methods (2015), pp.29-63

[10] Zhiwei Hu. The Research on the impact of masonry methods on the brick masonry mechanical properties. (2015), pp.50-66 